\title{
ANALISIS STRATEGI PENJUALAN STOK SPARE PART DI PT FAJAR MAS MURNI SURABAYA
}

\author{
Ida Purwanti ${ }^{1}$,Yuniar Farida ${ }^{2}$ \\ Jurusan Matematika, Fakultas Sains dan Teknologi, UIN Sunan Ampel Surabaya ${ }^{1,2}$ \\ Email : idapurwanti344@yahoo.co.id ${ }^{1}$, yuniar_farida@uinsby.ac.id ${ }^{2}$
}

DOI:https://doi.org/10.15642/mantik.2018.4.1.100-109

\begin{abstract}
Abstrak
Penelitian ini menggunakan studi kasus pada PT Fajar Mas Murni Surabaya yang bertujuan untuk mengklasifikasikan stok item spare part dengan pendekatan matriks BCG guna menentukan strategi penjualan stok item spare part. Hasil klasifikasi dengan matriks BCG diperoleh 6,60\% item termasuk dalam kuadran stars yang menyumbang omzet $80,67 \%$ bagi perusahaan; $15,57 \%$ item termasuk dalam kuadran question marks yang menyumbang omzet $14,95 \%$ bagi perusahaan; $71,70 \%$ item termasuk dalam kuadran dogs yang menyumbang omzet hanya $1,87 \%$ bagi perusahaan; $6,13 \%$ item termasuk dalam kuadran cash cows yang menyumbang omzet $2,50 \%$ bagi perusahaan. Analisis strategi yang sebaiknya dilakukan adalah: (1) pada kuadran stars sebaiknya dilakukan forecasting penjualan untuk menjaga kontinuitas stok spare part, (2) pada kuadran question marks sebaiknya dilakukan peningkatan nilai penjualan dengan menjual item secara diskon agar dapat menghabiskan stok, (3) pada kuadran dogs sebaiknya lebih meningkatkan kegiatan promosi dari item-item tersebut, (4) pada kuadran cash cows sebaiknya mempertahankan nilai penjualannya. Selanjutnya dilakukan forecasting penjualan pada item stok spare part kuadran stars pada tahun 2018 agar tetap terjaga kontinuitasnya dengan menggunakan metode Trend $(\mathrm{T})$ rata-rata bergerak dengan variasi siklus $(\mathrm{C})$, variasi musim (S), dan indeks gerak tak beraturan (I), diperoleh nilai MAPE sebesar 23\%. Jika hanya menggunakan metode Trend saja, diperoleh MAPE yang lebih besar, yakni $27 \%$.
\end{abstract}

Kata kunci: Pengendalian Persediaan, Matriks BCG, Forecasting, metode Trend dengan rata-rata bergerak

\begin{abstract}
This research uses a case study at PT Fajar Mas Murni Surabaya which aims to classify item of spare parts inventory with a BCG matrix approach to determine sales strategy of spare part inventory. The classification results with BCG matrix obtained 6,60\% items included in quadrant stars which contributed 80,67\% turnover for the company; $15,57 \%$ items included in the question marks quadrant which contributed $14,95 \%$ turnover for the company; $71,70 \%$ items included in the quadrant dogs which contributed only $1,87 \%$ turnover for the company; and $6,13 \%$ is included in the cash cows quadrant which contributes a $2,50 \%$ turnover for the company. The strategy analysis that should be carried out (1) on the stars quadrant is to forecast the sales to maintain the continuity of spare part inventory, (2) on the question marks quadrant is to develop the sales by selling items at a discount so that can increase sales volume and can spend inventory, (3) on the dogs quadrant is to further enhance the promotion activities of these items, (4) on the cash cows quadrant is to maintain sales. Then sales forecasting is carried out on stars quadrant spare parts inventory in 2018 so that continuity is maintained by using the Trend $(\mathrm{t})$ moving average ratio method with Cycle variation $(\mathrm{C})$, Season variation $(\mathrm{S})$, and Irregular movement (I), which obtained MAPE value of $23 \%$. If only using Trend, it obtained greater MAPE value of $27 \%$.
\end{abstract}

Keywords: Inventory Control, BCG Matrix, Forecasting, Trend with Moving Average 


\section{Pendahuluan}

Persediaan merupakan sumber utama penghasilan bagi perusahaan karena di dalam persediaan terdapat barang-barang dagangan yang dapat dijual sehingga menghasilkan laba bagi perusahaan. Dalam perusahaan dagang, persediaan adalah kumpulan barang yang disimpan dengan tujuan untuk dijual kembali tanpa mengubah apapun dari barang itu sendiri. Dalam persediaan, permasalahan yang krusial adalah adanya ketidaksesuaian antara jumlah barang yang disediakan dengan jumlah barang yang terjual, sehingga menimbulkan biaya penyimpanan yang berpotensi mengurangi laba perusahaan. Oleh karena itu, diperlukan pengendalian persediaan agar proses perencanaan terhadap pengadaan suatu barang dapat ditentukan seoptimal mungkin.

Salah satu perusahaan dagang yang berkembang adalah PT Fajar Mas Murni (FMM) Surabaya, sebuah perusahaan yang bergerak di bidang distributor penjualan alat-alat industri, konstruksi, pertambangan, dan laboratorium kesehatan. Selama ini pengendalian persediaan di PT FMM Surabaya masih belum menggunakan metode yang ilmiah dan tepat. Peneliti mencoba menerapkan pendekatan Matriks BCG (Boston Consulting Group) sebagai metode dalam inventory management di PT FMM Surabaya agar tidak terjadi kelebihan stok maupun kekurangan stok agar dapat meminimalisir biaya yang ditimbulkan dari adanya persediaan tersebut.

Adapun penelitian-penelitian yang berkaitan dengan pengendalian persediaan diantaranya adalah Analisis Pengendalian Perusahaan Menggunakan Pendekatan MUSIC 3D (Multi Unit Spares Inventory Control-Three Dimensional Approach) pada Warehouse di PT Semen Indonesia (PERSERO) Tbk Pabrik Tuban [1], Analisis Portopolio Produk pada PT. Asuransi Umum Bumiputeramuda 1967 Cabang Lampung Menggunakan Matrik Boston Consulting Group (BCG) [2], Analisis Pengendalian Persediaan Bahan Baku Ikan Tuna pada CV. Golden KK [3] , Analisis Matrik Boston Consulting Group (BCG) terhadap Portofolio Produk Guna Perencanaan Strategi Pemasaran dalam Menghadapi Persaingan [4], dan Analisis Matriks Boston Consulting Grup (BCG) pada Sepeda Motor Merek Honda (Studi
Kasus pada PT. Astra Honda Motor Tahun 2013) [5].

Pengendalian persediaan dapat didekati dengan beberapa metode seperti pada penelitianpenelitian sebelumnya yang pernah dilakukan. Pendekatan dengan matriks BCG yang dilakukan terhadap pengendalian persediaan masih belum pernah diterapkan namun karena tujuan akhirnya adalah mengoptimalkan penjualan persediaan spare part maka matriks BCG ini dimodifikasi dan diterapkan sebagai metode untuk menganalisa strategi penjualan stok spare part sebagai bagian dari pengendalian persediaan. Dengan menggunakan pendekatan matriks BCG, persediaan dikelompokkan menjadi 4 kelompok, yaitu kelompok Stars, Question Marks, Dogs, dan Cash Cows.

\section{Tinjauan Pustaka}

\subsection{Persediaaan}

Persediaan (inventory) adalah sumber daya ekonomi yang perlu diadakan dan dipelihara untuk menunjang kelancaran produksi. Sumber daya ekonomi tersebut dapat berupa kapasitas produksi, tenaga kerja, tenaga ahli, modal kerja, waktu yang tersedia, bahan baku, produk jadi, barang sedang dalam proses pengerjaan, serta bahan penolong [6]. Dalam perusahaan dagang, persediaan merupakan item yang dimiliki perusahaan yang tersimpan di gudang guna untuk dijual dalam jangka waktu tertentu. Persediaan timbul karena kuantitas item yang dibeli oleh perusahaan lebih besar dari kuantitas item yang terjual. Persediaan yang berlebihan akan menimbulkan biaya yang besar bagi perusahaan sehingga perusahaan perlu untuk melakukan pengendalian persediaan agar biaya yang timbul dapat diminimalisir.

\subsection{Pengendalian Persediaan}

Pengendalian persediaan merupakan proses pengelolaan persediaan guna untuk menjaga keseimbangan antara jumlah persediaan dengan biaya persediaan yang merupakan faktor penunjang dalam produktivitas. Salah satu tujuan adanya pengendalian persediaan adalah untuk mengoptimalkan persediaan agar perusahaan tidak kehabisan stok maupun kelebihan stok 
serta mengoptimalkan biaya pengadaan persediaan [7].

\subsection{Produk Spare Part}

PT FMM Surabaya memiliki banyak produk untuk dijual yang dikelompokkan menjadi 14 grup. Namun, pada penelitian ini produk yang dikaji adalah produk pada grup SPP-ASG yaitu spare part compressor. Spare part merupakan suatu produk yang terdiri dari lebih dari satu komponen yang membentuk satu kesatuan dan memiliki fungsi tertentu. Sedangkan compressor adalah alat yang digunakan untuk memasukkan, mengirim, dan menyediakan udara dengan tekanan tinggi [8]. Sehingga, spare part compressor merupakan suatu produk yang terdiri lebih dari satu komponen yang berfungsi untuk memasukkan, mengirim, dan menyediakan udara dengan tekanan tinggi.

\subsection{Matriks Boston Consulting Group}

Matriks BCG merupakan perencanaan portofolio model yang dikembangkan oleh Bruce Henderson yang berasal dari Boston Consulting Group pada tahun 1970. Boston Consulting Group merupakan perusahaan konsultan manajemen swasta yang berkecimpung dalam hal perkembangan pangsa pasar di Boston. Secara umum, matriks BCG digunakan untuk mengelola portofolio bisnis dengan mempertimbangkan posisi pangsa pasar relatif dan tingkat pertumbuhan instansi yang dapat membantu perusahaan dalam menganalisis unit bisnis atau lini produk [9]. Ide dari matriks BCG ini adalah setiap bisnis korporasi dapat dievaluasi dan diplot ke dalam sebuah matriks berukuran $2 \times 2$, sehingga dalam penelitian ini menggunakan pertimbangan posisi quantity out dan price untuk membantu perusahaan dalam menganalisis unit bisnis atau lini produk [10]. Berikut gambaran dari matriks BCG:

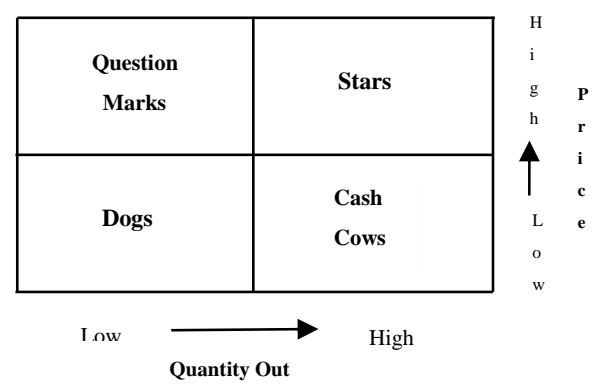

Gambar 1 Matriks BCG

Tujuan utama dari matriks BCG adalah untuk mengetahui item manakah yang layak mendapatkan perhatian khusus dan dukungan dana agar dapat bertahan dan menjadi kontributor terhadap kinerja perusahaan dalam jangka panjang. Metode analisis matriks BCG dapat membantu untuk mengetahui posisi instansi berdasarkan pada kombinasi dari quantity out dan price terhadap pesaing dalam 4 kelompok, yaitu [2]:

\section{Stars (Bintang)}

Kategori stars menggambarkan kondisi perusahaan yang penjualannya melesat sehingga kategori ini memiliki peluang terbaik dalam jangka panjang dalam hal pertumbuhan dan profit bagi perusahaan [10].Item yang masuk dalam kategori ini merupakan item yang memiliki quantity out (penjualan) tinggi dan price yang tinggi pula. Pada dasarnya, item-item tersebut dapat memberikan investasi yang besar bagi perusahaan sehingga dapat mempertahankan dan memperkuat posisi dominan perusahaan serta dapat memberikan arus kas yang positif.

\section{Cash Cows (Sapi Perah)}

Kategori cash cows menggambarkan kondisi perusahaan yang mengalami quantity out yang tinggi, tetapi memiliki price yang rendah. Kategori ini dinamakan cash cows karena menghasilkan kas yang lebih rendah dari yang dibutuhkan, sehingga perusahaan seringkali "diperah" [9]. Item yang masuk dalam kategori ini harus dikelola dengan baik guna mempertahankan posisi dalam jangka panjang.

\section{Dogs (Anjing)}

Kategori $\operatorname{dogs}$ menggambarkan kondisi perusahaan yang memiliki quantity out dan price rendah, sehingga mengakibatkan laba 
yang diterima perusahaan sangat kecil [9]. Kategori ini memerlukan beberapa investasi karena SDM dan sumber cost nya sangat rendah yang disebabkan oleh posisi internal dan eksternalnya lemah. Bisnis seperti ini seringkali dilikuidasi, di-divestasi, atau dipangkas dengan retrenchment. Retrenchment merupakan solusi yang terbaik dalam kategori ini karena banyak dogs yang muncul kembali setelah pemangkasan biaya dan aset secara besar-besaran menjadi bisnis yang dapat bertahan dan menguntungkan bagi perusahaan.

\section{Question Marks (Tanda Tanya}

Kondisi Question Marks menggambarkan keadaan perusahaan yang memiliki quantity out yang rendah tetapi memiliki price yang tinggi. Secara umum, kategori ini membutuhkan cost yang tinggi tapi cash in yang dihasilkan rendah [9]. Untuk mengatasi hal tersebut maka kategori ini lebih mudah ditingkatkan penjualannya. Hal tersebut dikarenakan item yang masuk dalam kategori ini bisa masuk dalam kategori stars. Apabila strategi tersebut dilaksanakan maka akan terjadi cash out dalam jangka pendek untuk melunasi penjualan dengan harapan akan terjadi hal sebaliknya yaitu terjadi cash in di kemudian hari. Kategori ini dinamakan Question Marks karena pihak perusahaan harus memberikan keputusan apakah akan memperkuat item-nya dengan menjalankan strategi ataukah item tersebut dibuang [2]. Terdapat 2 sumbu yang digunakan dalam matriks BCG, yaitu:

a. Sumbu vertikal, merupakan pembatasan terhadap price. Price yang dimaksud dalam penelitian ini adalah harga pokok pembelian dari masing-masing item. Harga pokok pembelian ini akan dievaluasi dan dibagi menjadi 2 kelompok, yaitu sebagai berikut:

1. High (tinggi)

Dengan menghitung rata-rata harga pokok pembelian pada persamaan berikut :

$$
\begin{aligned}
& \overline{\text { prlce }}=\frac{\sum H P P}{n} \\
& \text { Dimana : } \\
& \overline{\text { prlce }}=\text { price rata-rata } \\
& \sum H P P=\text { jumlah harga pokok } \\
& \quad \text { pembelian seluruh item }
\end{aligned}
$$




\subsection{Deret Berkala}

Terdapat 4 komponen dalam deret berkala, yaitu $\mathrm{T}$ (Trend), $\mathrm{S}$ (variasi musim), C (variasi siklus) dan I (indeks gerak tak beraturan) yang diringkas dalam persamaan berikut [11]:

$$
Y=T \times S \times C \times I
$$

Komponen yang pertama yaitu $T$ (Trend). Trend merupakan data yang memiliki kecenderungan gerakan meningkat atau menurun dari waktu ke waktu dalam jangka panjang. Pada penelitian ini digunakan metode kuadrat kecil.

\subsubsection{Metode Least Square (Kuadrat terkecil)}

Metode kuadrat terkecil merupakan salah satu metode analisis Trend untuk melakukan peramalan dengan menentukan garis Trend yang mempunyai jumlah paling kecil dari kuadrat selisih data aktual dengan data pada garis Trend. Berikut persamaan utuk mendapatkan garis Trend [11]:

$$
Y^{\prime}=a+b X
$$

Dimana :

$$
\begin{aligned}
& Y^{\prime}=\text { nilai trend hasil prediksi } \\
& a=\text { nilai konstanta } \\
& b=\text { nilai kemiringan } \\
& X=\text { nilai periode tahun }
\end{aligned}
$$

Untuk memperoleh nilai $a$ dan $b$ dapat menggunakan persamaan berikut :

$$
a=\frac{\sum Y}{n} b=\frac{\sum X Y}{\sum X^{2}}
$$

Komponen yang kedua yaitu $S$ (variasi musim). Variasi musim merupakan fluktuasi dalam musim-musim tertentu. Dalam penelitian ini menggunakan metode rasio rata-rata bergerak.

\subsubsection{Metode Rata-Rata Bergerak}

Pada metode rasio rata-rata bergerak (ratio to moving average method) dilakukan dengan membuat rata-rata bergerak selama periode tertentu. Nilai periode $(n)$ tergantung pada kondisi pengaruh fluktuasi musiman, bisa 2,3, 4, atau 12. Persamaan dari metode rasio rata-rata bergerak yaitu [11]:

\section{$S=$ nilai rasio $\times$ faktor koreksi}

dimana :

Nilai rasio = data aktual/data rata-rata bergerak
Faktor koreksi $=(100 \times n) /$ jumlahrata-rata rasio selama $n$

Komponen yang ketiga yaitu C (siklus). Dalam metode analisis variasi siklus dapat diperoleh dengan menggunakan indeks siklus.

\subsubsection{Indeks Siklus}

Siklus merupakan perubahan naik dan turun dalam suatu periode dan berulang pada periode lain. Jika Y, T, dan S telah diketahui maka CI dapat dicari dengan persamaan berikut [11]:

$$
\frac{Y}{S}=T \times C \times I
$$

Dimana $T \times C \times I$ menunjukkan data normal.

Untuk memperoleh faktor siklus maka unsur T (Trend) dikeluarkan dari data normal. Sehingga faktor siklus menjadi :

$$
C I=\frac{T C I}{T}
$$

Komponen yang keempat adalah I (gerak tak beraturan). Metode analisis gerak tak beraturan dapat diperoleh dengan mencari indeks gerak tak beraturan.

\subsubsection{Indeks Gerak Tak Beraturan}

Gerak tak beraturan (irregular movement) merupakan perubahan kenaikan dan penurunan yang tidak beraturan baik dari waktu dan lama siklusnya. Untuk mendapatkan indeks gerak beraturan, dapat dicari dengan membagi faktor siklus (CI) dengan (C) atau dapat disajikan dalam persamaan berikut [11]:

$$
I=\frac{C I}{C}
$$

\subsection{MAPE}

MAPE merupakan persentase kesalahan hasil prediksi atau peramalan terhadap nilai aktual selama periode tertentu. MAPE dinyatakan dalam persamaan berikut $[11,12]$ :

$M A P E=\left(\frac{100}{n}\right) \sum\left|P_{0}-\frac{P_{1}}{P_{0}}\right|$

Dengan :

$P_{0}=$ data aktual pada periode tertentu $P_{1}=$ hasil prediksi pada periode tertentu $n=$ jumlah periode peramalan 


\section{Metode Penelitian}

\subsection{Data}

a. Untuk melakukan klasifikasi persediaan dengan pendekatan matriks BCG digunakan data harga pokok pembelian dan jumlah item yang terjual pada tahun 2017. Data item tersebut merupakan data persediaan spare part compressor grup SPP-ASG sebanyak 212 item di PT FMM Surabaya.

b. Data yang digunakan untuk forecasting adalah data item stock pada kuadran stars (14 item) mulai tahun 2009 hingga tahun 2017.

\subsection{Langkah-langkah pengolahan data}

a. Menghitung total penjualan setiap item. Kemudian menghitung ratarata price dan rata-rata quantity out setiap item.

b. Mengelompokkan item pada price rendah atau tinggi. Price yang nilainya diatas rata-rata price maka dikelompokkan pada price tinggi, sedangkan ketika nilainya dibawah rata-rata price maka dikelompokkan pada price rendah.

c. Mengelompokkan item pada quantity out rendah atau tinggi. Quantity out yang nilainya diatas rata-rata quantity out maka dikelompokkan pada quantity out tinggi, sedangkan ketika nilainya dibawah rata-rata quantity out maka dikelompokkan pada quantity out rendah.

d. Mengklasifikasikan item-item pada 4 kuadran, yaitu kuadran stars, question marks, dogs, dan cash cows.

e. Melakukan forecasting pada item stars menggunakan metode Trend (T) rata-rata bergerak dengan variasi siklus (C), variasi musim (S), dan indeks gerak tak beraturan (I).

\section{Hasil dan Pembahasan}

\subsection{Klasifikasi dan Analisis Strategi Penjualan Stok Spare Part}

Berdasarkan matriks BCG terdapat 4 kuadran, yaitu stars, question marks (?), dogs dan cash cows. Berikut kategori masingmasing kuadran:

Tabel 1.Kategori Matriks BCG

\begin{tabular}{lcc}
\hline \multicolumn{1}{c}{ Kuadran } & quantity out & Price \\
\hline Stars & Tinggi & Tinggi \\
$(?)$ & Rendah & Tinggi \\
Dogs & Rendah & Rendah \\
Cash cows & Tinggi & Rendah \\
\hline
\end{tabular}

Dengan menggunakan persamaan (1) diperoleh rata-rata price sebesar $R p$ 5.498.706.51 $\approx R p$ 5.000.000,-

Item yang memiliki price lebih dari Rp. 5.000.000,- masuk dalam golongan tinggi, sedangkan item yang price -nya kurang dari Rp. 5.000.000,- masuk dalam golongan rendah.

Dengan menggunakan persamaan (2) rata-rata quantity out sebanyak $9,04717 \approx 9$. Item yang memiliki quantity out lebih dari 9 masuk dalam golongan tinggi, sedangkan item yang quantity out-nya kurang dari 9 masuk dalam golongan rendah.

Hubungan price dan quantity out dapat digambarkan dalam matriks BCG seperti ditunjukkan pada Gambar 3.

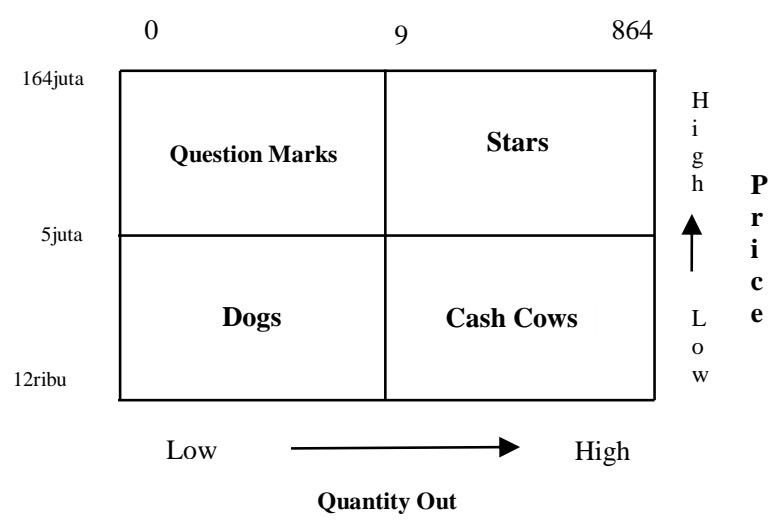

Gambar 3 Gambaran Matriks BCG PT Fajar Mas Murni Surabaya

Berdasarkan gambar di atas, diperoleh klasifikasi item dalam 4 kelompok, yaitu: 


\subsubsection{Kuadran Stars}

Pada mulanya, terdapat 6 item spare part yang tergolong dalam kuadran I (stars). Pada kelompok stars, item-item tersebut berada pada posisi quantity out (penjualan) yang tinggi dan price (harga pokok pembelian) yang tinggi pula, yakni penjualannya lebih dari 9 unit dalam 1 tahun dan harga pokok pembeliannya lebih dari $\mathrm{Rp}$ 5.000.000

Selanjutnya, dilakukan analisa kembali pada total penjualan masing-masing item, dengan menghitung rata-rata penjualannya. Diperoleh rata-rata total penjualan sebesar $\mathrm{Rp} 29.463 .392 .90 \approx \mathrm{Rp} 29.000 .000$. Item yang memiliki nilai total penjualan lebih dari $R p$ 29.000.000 digolongkan dalam total penjualan tinggi, sedangkan item yang memiliki nilai total penjualan kurang dari $R p$ 29.000.000 digolongkan dalam total penjualan rendah. Sehingga, terdapat tambahan 8 item lagi yang dapat masuk ke dalam kelompok stars. Mulanya, 8 item tersebut masuk dalam kelompok cash cows namun karena item tersebut memiliki total penjualan yang tinggi yaitu lebih dari $R p$ 29.000.000 maka 8 item tersebut dapat tergolong menjadi kelompok stars.

Oleh karena itu, jumlah keseluruhan item spare part yang tergolong dalam kelompok stars sebanyak 14 item yang ditunjukkan pada Tabel 2.

Tabel 2. Kelompok Stars

\begin{tabular}{ccccr}
\hline No. & Part Number & Out & \multicolumn{2}{c}{ Total penjualan } \\
\hline 1 & 38459582 & 846 & $\mathrm{Rp}$ & $3.353 .350 .638,24$ \\
2 & 54509435 & 23 & $\mathrm{Rp}$ & $407.851 .468,42$ \\
3 & 22219174 & 22 & $\mathrm{Rp}$ & $306.562 .073,84$ \\
4 & 54509427 & 17 & $\mathrm{Rp}$ & $129.661 .821,83$ \\
5 & 39863857 & 13 & $\mathrm{Rp}$ & $92.336 .668,19$ \\
6 & 67731158 & 12 & $\mathrm{Rp}$ & $60.708 .004,68$ \\
7 & 39903281 & 215 & $\mathrm{Rp}$ & $200.134 .123,85$ \\
8 & 39911631 & 112 & $\mathrm{Rp}$ & $132.236 .016,64$ \\
9 & 54601513 & 38 & $\mathrm{Rp}$ & $99.393 .725,68$ \\
10 & 39708466 & 132 & $\mathrm{Rp}$ & $75.115 .659,96$ \\
11 & 54749247 & 52 & $\mathrm{Rp}$ & $64.705 .755,40$ \\
12 & 22089551 & 20 & $\mathrm{Rp}$ & $48.362 .085,80$ \\
13 & 89237903 & 34 & $\mathrm{Rp}$ & $35.111 .932,26$ \\
14 & 39911615 & 49 & $\mathrm{Rp}$ & $34.268 .409,21$ \\
\hline
\end{tabular}

Dari $6,6 \%$ item tersebut dapat disimpulkan bahwa kelompok stars menyumbang $80,67 \%$ penjualan bagi perusahaan. Secara umum, kuadran stars ini memiliki margin yang kecil namun omzet penjualannya besar karena rata-rata item-item tersebut dijual dengan diskon dengan tujuan untuk mengejar volume penjualan. Sehingga, kontinuitas stok item tersebut perlu dijaga agar tidak kehabisan stok. Karena kuadran stars memiliki total penjualan yang besar bagi perusahaan, maka item-item pada kuadran ini harus dipertahankan.

Salah satu alternatif strategi untuk mempertahankan kuadran stars ini adalah dengan melakukan forecasting penjualan persediaan agar tetap menjaga kontinuitas stok item.

\subsubsection{Kuadran Question Marks}

Terdapat 33 item spare part yang tergolong dalam kuadran II (question marks) yang ditunjukkan pada Tabel 3.

Tabel 3. Kelompok Question Marks

\begin{tabular}{|c|c|c|c|c|}
\hline No. & Part Number & Out & \multicolumn{2}{|c|}{ Total Penjualan } \\
\hline 1 & 39433743 PLT & 3 & $\mathrm{Rp}$ & $490.079 .640,63$ \\
\hline 2 & 39433743 & 7 & $\mathrm{Rp}$ & $285.879 .790,35$ \\
\hline 3 & 92722750 & 5 & $\mathrm{Rp}$ & $31.890 .772,90$ \\
\hline 4 & 39817655 & 2 & $\mathrm{Rp}$ & $29.631 .003,28$ \\
\hline 5 & 43074947 & 1 & $\mathrm{Rp}$ & $29.349 .036,40$ \\
\hline 6 & 22110399 & 1 & $\mathrm{Rp}$ & $29.197 .779,07$ \\
\hline 7 & 39807532 & 2 & $\mathrm{Rp}$ & $27.868 .964,22$ \\
\hline 8 & 22699706 & 1 & $\mathrm{Rp}$ & $9.889 .346,02$ \\
\hline 9 & 00446575 & 0 & $\mathrm{Rp}$ & \\
\hline 10 & 42447177 & 0 & $\mathrm{Rp}$ & \\
\hline . & . & . & & . \\
\hline . & . & . & & . \\
\hline 33 & 39844113 & 0 & $\mathrm{Rp}$ & \\
\hline
\end{tabular}

Pada kuadran question marks, item-item tersebut berada pada posisi quantity out yang rendah dan price yang tinggi. Dimana penjualannya kurang dari 9 unit dalam 1 tahun dan harga pokok pembeliannya lebih dari Rp 5.000.000. Sebanyak 15,57\% item masuk pada kuadran question marks menyumbang $14,95 \%$ penjualan bagi perusahaan. Item yang termasuk dalam kuadran ini merupakan item yang memiliki resiko tinggi untuk distok karena telah tersubstitusi oleh produk lain dan juga memiliki price yang tinggi sehingga penjualanna menjadi rendah.

Alternatif strategi yang sebaiknya dilakukan adalah mengembangkan nilai penjualan dengan menjual diskon agar terjadi peningkatan volume penjualan dan dapat menghabiskan stok.

\subsubsection{Kuadran Dogs}

Terdapat 152 item spare part yang tergolong dalam kuadran III $(\operatorname{dog} s)$. Pada kelompok dogs, item-item tersebut berada 
pada posisi quantity out yang rendah dan price yang rendah pula. Dimana penjualannya kurang dari 9 unit dalam 1 tahun dan harga pokok pembeliannya kurang dari Rp 5.000.000. Sebanyak 71,70\% item masuk pada kuadran dogs dan hanya menyumbang $1,87 \%$ penjualan bagi perusahaan.

Alternatif strategi yang sebaiknya dilakukan adalah lebih meningkatkan kegiatan promosi agar nilai penjualan item tersebut meningkat.

\subsubsection{Kuadran Cash Cows}

Terdapat 21 item spare part yang tergolong dalam kuadran IV (cash cows). Pada kelompok sapi perah, item-item tersebut berada pada posisi quantity out yang tinggi dan price yang rendah. Pada kuadran sapi perah memiliki penjualan yang lebih dari 9 unit dalam 1 tahun dan harga pokok pembeliannya kurang dari Rp 5.000.000. Kemudian dilakukan analisa kembali pada total penjualan masing-masing item dengan menggunakan persamaan (1). Item yang memiliki nilai total penjualan lebih dari $R p$ 29.000.000 digolongkan dalam total penjualan tinggi, sedangkan item yang memiliki nilai total penjualan kurang dari $R p 29.000 .000$ digolongkan dalam total penjualan rendah.

Terdapat 8 item cash cows yang dapat masuk pada kelompok stars karena item tersebut memiliki total penjualan yang tinggi yaitu lebih dari $R p$ 29.000.000. Oleh karena itu, jumlah keseluruhan item spare part yang tergolong dalam kelompok cash cows sebanyak 13 item yaitu sebagai berikut:

Tabel 4. Kelompok Cash Cows

\begin{tabular}{ccccc}
\hline No. & Part Number & Out & \multicolumn{2}{c}{ Total Penjualan } \\
\hline 1 & 37952355 & 28 & $\mathrm{Rp}$ & $28.850 .378,76$ \\
2 & 22334155 & 10 & $\mathrm{Rp}$ & $26.929 .326,10$ \\
3 & 46866331 & 15 & $\mathrm{Rp}$ & $23.247 .761,40$ \\
4 & 54672654 & 35 & $\mathrm{Rp}$ & $16.694 .706,70$ \\
5 & 39907175 & 25 & $\mathrm{Rp}$ & $11.869 .352,00$ \\
6 & 22203095 & 14 & $\mathrm{Rp}$ & $11.054 .323,56$ \\
7 & 37952264 & 11 & $\mathrm{Rp}$ & $8.053 .531,86$ \\
8 & 39155478 & 32 & $\mathrm{Rp}$ & $7.237 .623,68$ \\
9 & 32012957 & 9 & $\mathrm{Rp}$ & $5.664 .898,44$ \\
10 & 39588470 & 11 & $\mathrm{Rp}$ & $4.802 .033,50$ \\
11 & 89295976 & 10 & $\mathrm{Rp}$ & $4.816 .236,80$ \\
12 & 67500892 & 9 & $\mathrm{Rp}$ & $3.976 .906,68$ \\
13 & 39194915 & 12 & $\mathrm{Rp}$ & $2.846 .740,56$ \\
\hline
\end{tabular}

Sebanyak $6,13 \%$ item masuk pada kuadran cash cows menyumbang 2,50\% penjualan bagi perusahaan. Pada cash cows ini, perusahaan berusaha mendapatkan margin yang besar karena para pelanggan sudah banyak meng-order item-item tersebut karena harga jual item tersebut murah. Sehingga alternatif strategi yang sebaiknya dilakukan adalah dengan mempertahankan nilai penjualan.

\subsubsection{Diagram Hasil Matriks BCG}

Dari pembahasan di atas, diperoleh diagram akhir matriks BCG PT Fajar Mas Murni Surabaya ketika menggunakan kombinasi antara quantity out dan price yang disajikan dalam Gambar 4.

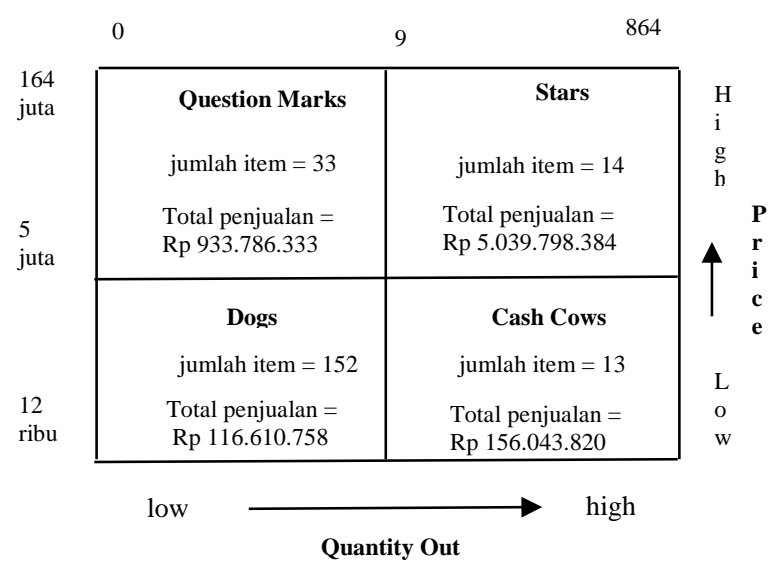

\section{Gambar 4 Hasil Akhir Klasifikasi Matriks BCG}

Berdasarkan pendekatan matriks BCG, diperoleh persentase akhir item 6,60\% yang termasuk dalam kuadran stars, kuadran question marks sebesar 15,57\%, kuadran dogs sebesar $71,70 \%$ dan pada kuadran cash cows diperoleh persentase item sebesar $6,13 \%$ sebagaimana ditunjukkan pada Gambar 5.

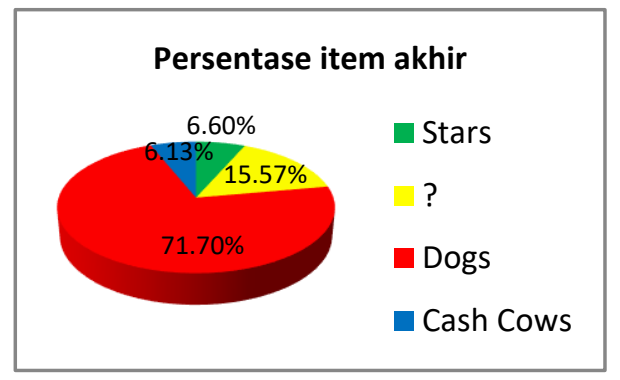

Gambar 5 Persentase Item Akhir 
Sedangkan diagram persentase penjualan matriks BCG dapat disajikan pada Gambar 6.

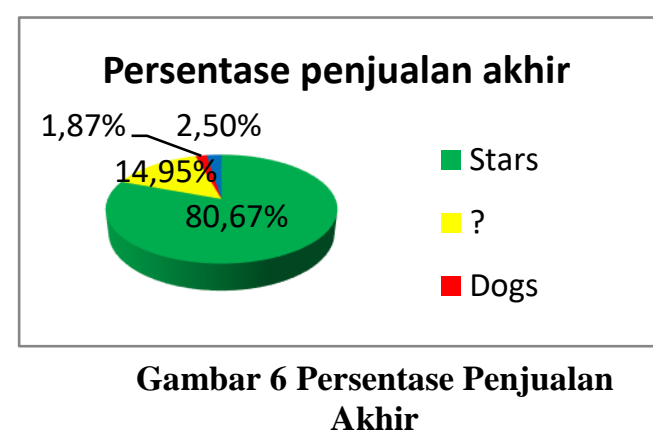

Berdasarkan pendekatan matriks BCG, kuadran stars menyumbang 80,67\% omzet penjualan, kuadran question marks menyumbang $14,95 \%$ omzet penjualan, kuadran dogs hanya menyumbang omzet penjualan sebesar $1,87 \%$ dan pada kuadran cash cows menyumbang 2,50\% omzet penjualan bagi perusahaan.

\subsection{Forecasting Penjualan}

Pada penelitian ini dilakukan peramalan penjualan item stok kuadran stars di tahun 2018 dengan menggunakan metode analisis variasi siklus yang menggabungkan 4 komponen yaitu Trend, musim, siklus, dan indeks gerak tak beraturan.

Langkah awal dalam melakukan forecasting penjualan yaitu mencari nilai trend $(\mathrm{T})$ dengan metode kuadrat terkecil seperti pada Persamaan (4) diperoleh $Y^{\prime}=$ $347,667-0,181 X$, dengan memasukkan nilai $X$ sesuai periode waktu yang akan diramalkan sehingga diperoleh hasil pramalan penjualan tahun 2018 pada item dengan part number 38459582 sebesar $1.034,856 \approx 1.035$.

Kemudian variasi musim dihitung dengan metode rasio rata-rata bergerak seperti pada Persamaan (6) sehingga diperoleh indeks musim (S) kuartalan yang dikalikan dengan faktor koreksi sebagai berikut:

Indeks triwulan $\mathrm{I}=1,13687156 \times$ $0,996441=1,1328225101$

Indeks triwulan II $=1,00814955 \times$ $0,996441=1,004561253$
Indeks triwulan III $=0,86569491 \times$ $0,996441=0,862613646$

Selanjutnya variasi siklus dihitung dengan menggunakan indeks siklus (C) dalam persamaan (7) dan (8) diperoleh $(0,8529611+1,1447773+1,1901608) / 3=$ 1,0626331, kemudian gerak tak beraturan (I) dihitung dengan Persamaan (9) diperoleh $(0,9812825+0,9779907+1,0739391) / 3=$ 1,0110708 .

Setelah diperoleh nilai Trend, indeks musim, indeks siklus, dan indeks gerak tak beraturan (TSCI) maka langkah yang terakhir yaitu menggabungkan 4 komponen tersebut dengan Persamaan (3) sehingga diperoleh prediksi penjualan tahun 2018 pada item dengan part number 38459582 sebesar $1.111,899 \approx 1.112$. Hasil peramalan penjualan dari masing-masing item kuadran stars disajikan pada Tabel 5.

Tabel 5. Hasil Prediksi penjualan tahun 2018

\begin{tabular}{rccc}
\hline No. & $\begin{array}{c}\text { Part } \\
\text { Number }\end{array}$ & $\begin{array}{c}\text { Hasil } \\
\text { Prediksi } \\
\text { 2018 (T) }\end{array}$ & $\begin{array}{c}\text { Hasil } \\
\text { Prediksi } \\
\text { 2018 (TSCI) }\end{array}$ \\
\hline 1 & 38459582 & 1035 & 1112 \\
2 & 54509435 & 138 & 141 \\
3 & 22219174 & 103 & 90 \\
4 & 54509427 & 91 & 54 \\
5 & 39863857 & 50 & 20 \\
6 & 67731158 & 19 & 14 \\
7 & 39903281 & 15 & 10 \\
8 & 39911631 & 12 & 13 \\
9 & 54601513 & 6 & 4 \\
10 & 39708466 & 33 & 35 \\
11 & 54749247 & 60 & 63 \\
12 & 22089551 & 24 & 13 \\
13 & 89237903 & 10 & 6 \\
14 & 39911615 & 46 & 44 \\
\hline
\end{tabular}

Dari Tabel 5 terlihat bahwa hasil peramalan penjualan ketika hanya menggunakan metode Trend dengan variasi 4 komponen (TSCI) tidak jauh berbeda dengan hanya menggunakan metode Trend saja. Namun, hasil peramalan ketika menggunakan 4 komponen (TSCI) menghasilkan nilai MAPE (pers. 10) sebesar $23 \%$ yang lebih kecil daripada ketika hanya menggunakan metode Trend saja, yaitu $27 \%$. 


\section{Simpulan}

Berdasarkan pendekatan matriks BCG, diperoleh klasifikasi persediaan item spare part menjadi 4 kuadran yaitu kuadran stars terdapat 14 item, kuadran question marks terdapat 33 item, kuadran dogs terdapat 152 item, dan kuadran cash cows terdapat 13 item.

Analisis strategi yang sebaiknya dilakukan di tiap kuadran adalah: (1) pada kuadran stars sebaiknya dilakukan forecasting penjualan untuk menjaga kontinuitas stok spare part, (2) pada kuadran question marks sebaiknya dilakukan peningkatan nilai penjualan dengan menjual item secara diskon agar dapat menghabiskan stok, (3) pada kuadran dogs sebaiknya lebih meningkatkan kegiatan promosi dari item-item tersebut, (4) pada kuadran cash cows sebaiknya mempertahankan nilai penjualannya.

Hasil peramalan atau forecasting penjualan stok spare part dalam kurun waktu 1 tahun mendatang yaitu tahun 2018 pada kuadran stars dilakukan dengan metode Trend rasio ratarata bergerak dengan variasi musim, siklus, dan gerak tak beraturan karena menghasilkan nilai kesalahan MAPE yang lebih kecil (23\%) daripada hanya dengan menggunakan metode Trend saja (27\%).

\section{Referensi}

[1] D. Janari, M. M. Rahman dan A. R. Anugerah, "Analisis Pengendalian Perusahaan Menggunakan Pendekatan MUSIC 3D (Multi Unit Spares Inventory Control-Three Dimensional Approach) pada Warehouse di PT Semen Indonesia (PERSERO) Tbk Pabrik Tuban," Teknoin, vol. 22, no. 4, pp. 261-268, 2016.

[2] M. Y. S. Barusman dan S. Gunardi, "Analisis Portopolio Produk Pada PT. Asuransi Umum Bumiputeramuda 1967 Cabang Lampung Menggunakan Matrik
Boston Consulting Group (BCG),' Jurnal Manajemen dan Bisnis, p. 1, 2014.

[3] M. C. Tuerah, "Analisis Pengendalian Persediaan Bahan Baku Ikan Tuna pada CV. Golden KK," EMBA, vol. 2, no. 4, pp. 524-536, 2014.

[4] W. Wahyuandari, "Analisis Matrik Boston Consulting Group (BCG) Terhadap Portofolio Produk Guna Perencanaan Strategi Pemasaran dalam Menghadapi Persaingan," Jurnal Universitas Tulungagung BONOROWO, vol. 1, no. 1, pp. 88-104, 2013.

[5] Y. S. Putra, "Analisis Matriks Boston Consulting Grup (BCG) pada Sepeda Motor Merek Honda (Studi Kasus pada PT. Astra Honda Motor Tahun 2013)," Among Makarti, vol. 7, no. 13, pp. 48-71, 2014.

[6] M. Haming dan M. Nurnajamuddin, Manajemen Produksi Modern, Jakarta: PT Bumi Aksara, 2017.

[7] A. Wibisono, "Penerapan Analisis ABC dalam Pengendalian Persediaan Produk Furniture pada Java Furniture, Wonosari, Klaten," Universitas Sebelas Maret, Surakarta, 2009.

[8] Aditiya, "Makalah Kompresor," Universitas Sarjanawiyata Tamansiswa Yogyakarta, Yogyakarta, 2003.

[9] R. P. Suci, Esensi Manajemen Strategi, Sidoarjo: zifatama, 2015.

[10] Hery, Manajemen Strategik, Jakarta: PT Grasindo, 2018.

[11] Suharyadi dan Purwanto, Statistika untuk Ekonomi dan Keuangan Modern, Jakarta: Salemba Empat, 2017.

[12] R. L. R. d. G. D. Yogo Aryo Jatmiko, Perbandingan Keakuratan Hasil Peramalan Produksi Bawang Merah Metode Holt-Winters dengan Singular Spectrum Analysis (SSA)", mantik, 2017. 